\title{
ИССЛЕДОВАНИЕ КРАТКОСРОЧНОЙ КРИВОЙ ФИЛЛИПСА И СТАНОВЛЕНИЯ РЫНКА ТРУДА В РОССИЙСКОЙ ФЕДЕРАЦИИ
}

\section{STUDY OF THE SHORT-TERM PHILLIPS CURVE AND THE FORMATION \\ OF THE LABOR MARKET IN THE RUSSIAN FEDERATION}

D. Ujakov

E. Nayanov

O. Ignatyeva

Summary. Inflation and unemployment are key macroeconomic alternative representation of the aggregate supply. The analysis carried method of a conscious choice between inflation and unemployment and presents a model of the influence of these indicators on the labor market and sustainable economic growth.

Keywords: inflation rate, unemployment rate, Phillips curve, regression analysis, price growth rate, wage growth rate, Solow model. indicators. The Phillips curve, which is discussed in this article, is an out in this work makes it possible to regulate aggregate demand by the

\author{
Ужаков Демьян \\ ФГБОУ ВО «Московский политехнический \\ университет» \\ mister-231996@mail.ru \\ Наянов Евгений Александрович \\ Старший преподаватель, ФГБОУ ВО «Московский \\ политехнический университет» \\ e.a.nayanov@mospolytech.ru \\ Игнатьева Ольга Валерьевна \\ К.ю.н., Дочент, ФГБОУ ВО «Московский \\ политехнический университет» \\ oignatyeva@mail.ru
}

Аннотация. Инфляция и безработица — ключевые макроэкономические показатели. Кривая Филлипса, рассматривается в данной статье как альтернативный вариант представления совокупного предложения. Анализ, проведенный в данной работе, позволяет регулировать совокупный спрос методом осознанного выбора между инфляцией и безработицей, а также представлена модель влияния данных показателей на рынок труда и устойчивый рост экономики.

Ключевые слова: темп инфляции, уровень безработицы, кривая Филлипса, регрессионный анализ, темп роста цен, темп роста заработной платы, модель Солоу.

3. современная кривая Филлипса дополнена показателем шоковых изменений предложения.

$\pi=\pi^{e}-\beta\left(u-u^{e}\right)+\varepsilon$

утверждение промышленности в качестве главного стимула и фактора экономического прогресса; 2) отток рабочей силы из аграрного сектора (рис. 1).

Позитивное влияние глобализации на сферу труда не проходит безболезненно для национальной экономики, так как рабочая сила - это наименее мобильный фактор. Все это приводит к росту безработицы.

Кривая Филлипса была названа в честь английского экономиста А.В. Филлипса, который впервые обнаружил обратную связь между уровнем безработицы и темпами прироста номинальной заработной платы. В настоящее время используется анализ, который отличается от выведенного Филлипсом по трем направлениям (1):

1. в настоящее время темпы прироста заработной платы заменены на темпы инфляции;

2. в 60-е годы $X X$ века Милтон Фридмен и Эдмунд Фелпс дополнили уравнение кривой Филлипса ожидаемыми темпами инфляции; где, $\pi$ - инфляция

$\pi$ - ожидаемая инфляция;

$u-u^{e}$ - циклическая безработица;

$\varepsilon$ - шоки предложения;

$\beta$ - параметр, который показывает насколько сильно инфляция на циклическую безработицу.

Так как инфляция и безработица - основные макроэкономические показатели, кривую Филлипса часто используют для анализа экономической ситуации в стране. На рисунке 2 представлены данные по изменению инфляции и безработицы в Российской Федерации начиная с 2000 года [2, 5].

Как мы видим из рисунка в начале 2000 года наблюдается самый пик инфляции и безработицы - это связано с переломным моментом в экономике Российской Федерации, переход от планового ведения хозяйства 


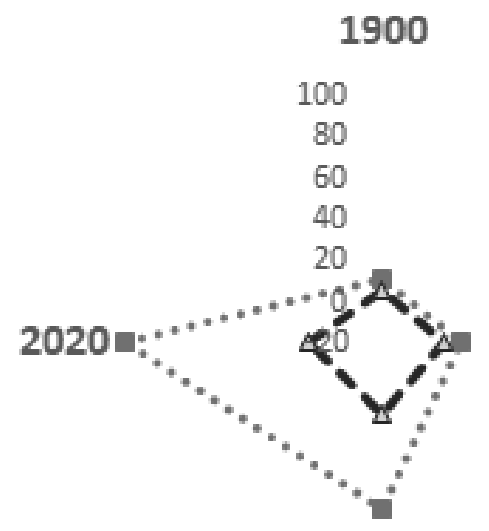

\section{0}

...... Развитые страны - -

Рис. 1. Изменение в производительности труда
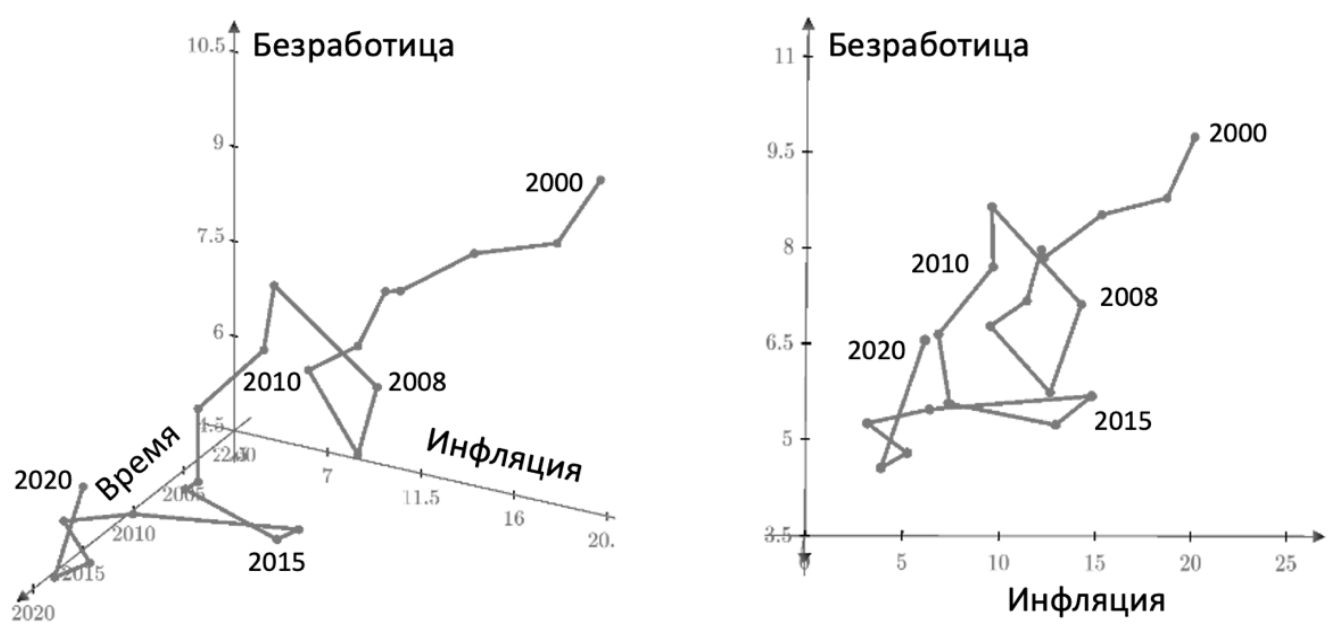

Рис. 2. Инфляция и безработица в Российской Федерации (пространственная модель и проекция)

к рыночному привел к сокращению рабочих мест. Далее наблюдается спад уровней инфляции и безработицы на фоне роста цен на нефть и политикой Центрального Банка по снижению инфляции, следующий скачок в 2008 году - влияние мирового финансового кризиса, в 2015 году - введение рядом стран санкций в отношении России и изменением политики ЦБ в области валютного курса страны. Эпидемия новой коронавирусной инфекции тоже внесла свой вклад в изменение показателей и в 2020 году наблюдается рост безработицы.

Рассмотрим возможности, которые представляет нам кривая Филлипса для анализа экономической по- литики, которая направлена на управление совокупным спросом.

В таблице 1 представлены данные для построения кривой Филллипса для Российской экономики [2].

Подставляя данные (табл. 1) в уравнение 1 и используя параметрический анализ в Microsoft Excel, получаем следующую уравнение краткосрочной кривой Филлипса для экономики РФ [7] (2)

$$
\pi=-224,85+1314 \times \frac{1}{U}
$$


Таблица 1. Показатели безработицы и инфляции Российской Федерации

\begin{tabular}{|c|c|c|c|c|}
\hline Даты & Безработица & Инфляция & Темп инфляции & $1 / U$ \\
\hline янв.18 & 0,31 & 5,2 & - & - \\
\hline февр.18 & 0,21 & 5 & $-32,26$ & 0,20 \\
\hline март.18 & 0,29 & 5 & 38,10 & 0,20 \\
\hline апр.18 & 0,38 & 4,9 & 31,03 & 0,20 \\
\hline май.18 & 0,38 & 4,7 & 0,00 & 0,21 \\
\hline июнь. 18 & 0,49 & 4,7 & 28,95 & 0,21 \\
\hline июль. 18 & 0,27 & 4,7 & $-44,90$ & 0,21 \\
\hline авг.18 & 0,01 & 4,6 & $-96,30$ & 0,22 \\
\hline сент.18 & 0,16 & 4,5 & 1500,00 & 0,22 \\
\hline ОКт.18 & 0,35 & 4,7 & 118,75 & 0,21 \\
\hline нояб.18 & 0,5 & 4,8 & 42,86 & 0,21 \\
\hline дек.18 & 0,84 & 4,8 & 68,00 & 0,21 \\
\hline янв.19 & 1,01 & 4,8 & 20,24 & 0,21 \\
\hline февр.19 & 0,44 & 4,9 & $-56,44$ & 0,20 \\
\hline март.19 & 0,32 & 4,7 & $-27,27$ & 0,21 \\
\hline апр.19 & 0,29 & 4,7 & $-9,38$ & 0,21 \\
\hline май.19 & 0,34 & 4,5 & 17,24 & 0,22 \\
\hline июнь.19 & 0,04 & 4,4 & $-88,24$ & 0,23 \\
\hline июль.19 & 0,2 & 4,5 & 400,00 & 0,22 \\
\hline авг.19 & $-0,24$ & 4,3 & $-220,00$ & 0,23 \\
\hline сент.19 & $-0,16$ & 4,5 & $-33,33$ & 0,22 \\
\hline OKT.19 & 0,13 & 4,6 & $-181,25$ & 0,22 \\
\hline нояб.19 & 0,28 & 4,6 & 115,38 & 0,22 \\
\hline дек.19 & 0,36 & 4,6 & 28,57 & 0,22 \\
\hline янв.20 & 0,4 & 4,7 & 11,11 & 0,21 \\
\hline февр.20 & 0,33 & 4,6 & $-17,50$ & 0,22 \\
\hline март.20 & 0,55 & 4,7 & 66,67 & 0,21 \\
\hline апр.20 & 0,83 & 5,8 & 50,91 & 0,17 \\
\hline май.20 & 0,27 & 6,1 & $-67,47$ & 0,16 \\
\hline июнь.20 & 0,22 & 6,2 & $-18,52$ & 0,16 \\
\hline июль.20 & 0,35 & 6,3 & 59,09 & 0,16 \\
\hline авг.20 & $-0,04$ & 6,4 & $-111,43$ & 0,16 \\
\hline сент.20 & $-0,07$ & 6,3 & 75,00 & 0,16 \\
\hline ОКТ.20 & 0,43 & 6,3 & $-714,29$ & 0,16 \\
\hline нояб.20 & 0,71 & 6,1 & 65,12 & 0,16 \\
\hline дек.20 & 0,83 & 5,9 & 16,90 & 0,17 \\
\hline
\end{tabular}

Результаты расчетов на основании уравнения 2 представлены на рис. 3.

В результате построения, можно утверждать, что одновременное существование высокой инфляции и безработицы невозможно. Краткосрочная кривая Филлипса зависит от ожидаемых темпов инфляции, в период, когда ожидаемая инфляция растет - кривая сдвигается вверх. Виду того, что население меняет свои взгляды относительно рациональных ожиданий по инфляции, выбор между безработицей и инфляцией существует только в краткосрочном периоде, так как в долгосрочном периоде безработица возвращается своему естественному уровню
Многие исследователи [4], сводят анализ кривой Филлипса к расчету соотношения потерь ВВП от антиинфляционной политики. В результате такого анализа можно определить сколько процентов реального ВВП нужно принести в жертву ради сокращения инфляции на 1\%. Используя закон Оукена [3], соотношение потерь можно так же выразить через безработицу. На рисунке 4 представлены результаты расчетов борьбы с инфляции и отклонение ВВП России на период до 2023 года. Как мы видим, антиинфляционная политика приносит ВВП в среднем около 18622 млрд. руб, а безработица съедает - 6262 млрд. руб. [1, 6] 
Таблица 2. Уровни безработицы во время борьбы с инфляцией

\begin{tabular}{|l|l|l|l|l|}
\hline Год & Уровень инфляции & Уровень безработицы & Естественное значение & $\begin{array}{l}\text { Циклическая } \\
\text { безработица }\end{array}$ \\
\hline 2017 & 2,52 & 5,2 & 5,2 & 0 \\
\hline 2018 & 4,27 & 4,8 & 5,2 & $-0,4$ \\
\hline 2019 & 3,05 & 4,6 & 5,2 & $-0,6$ \\
\hline 2020 & 4,91 & 6,3 & 5,2 & 1,1 \\
\hline & & & Всего & 0,1 \\
\hline
\end{tabular}

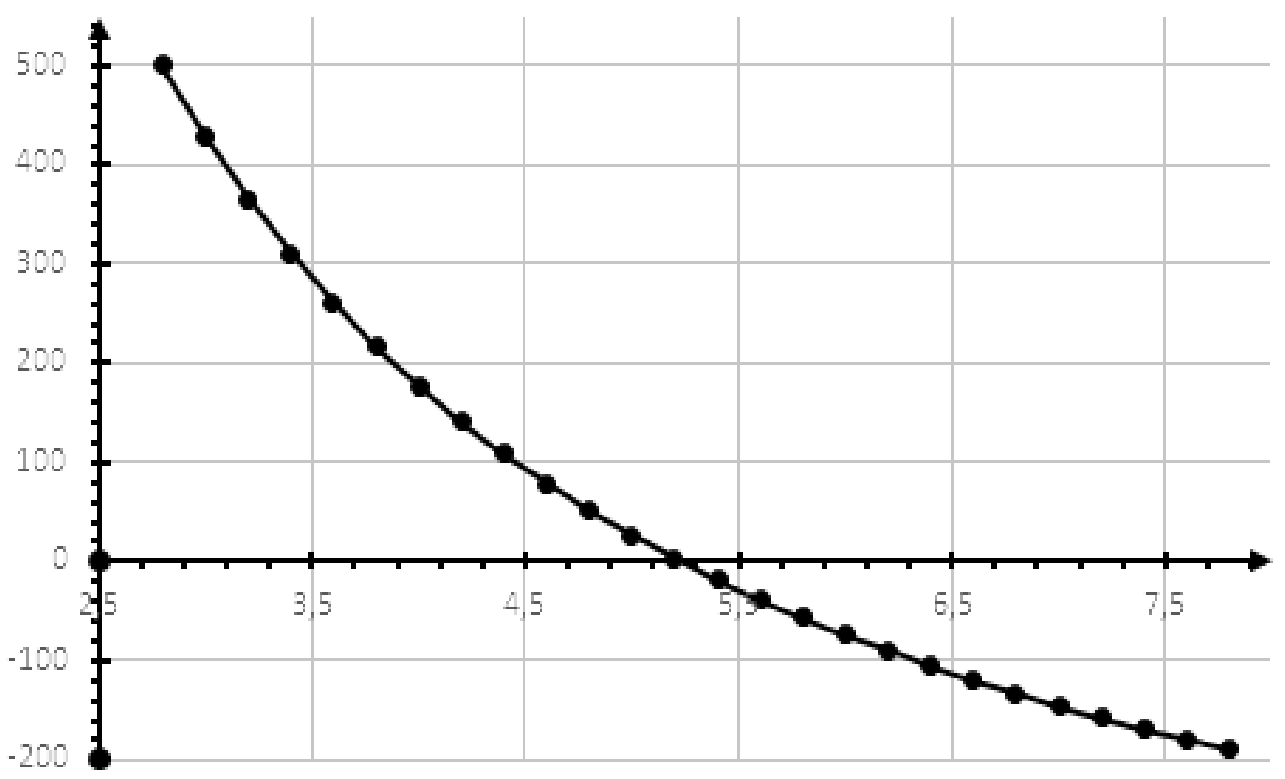

Рис. 3. Краткосрочная кривая Филлипса

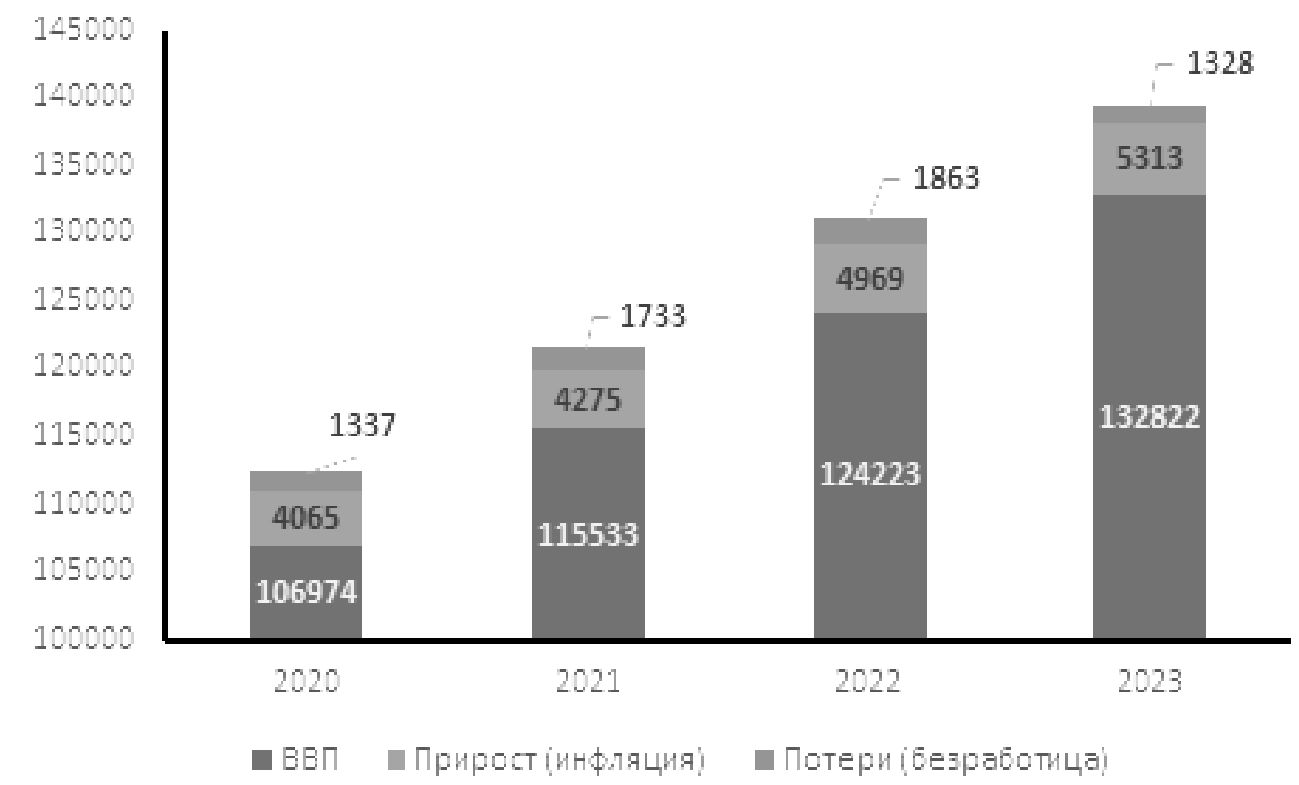

Рис. 4. Потери ВВП в результате антиинфляционной политики 
Рассмотрим возможности, которые нам дает кривая Филлипса для анализа макроэкономической ситуации в стране (табл. 2). Как мы видим из данной таблицы, в целом за период борьбы с инфляцией циклическая безработица составила 0,1\%. Согласно закону Оукена, $1 \%$ прироста безработицы, дает отставание фактического ВВП от потенциального 2,5\%. Следовательно, за период потери в ВВП составили 0,25\%.

\section{Выво $\triangle \mathrm{b}$}

Таким образом, проанализировав кривую Филлипса можно сделать следующие выводы:

1. кривую Филлипса можно использовать для разработки экономической политики регулирования совокупного спроса;
2. общее падение числа экономически активного населения в России за период 2017-2020 года говорит о том, что увеличивается уровень безработицы;

3. возрастает уровень естественной безработицы, что говорит нам о росте числа безработных невостребованных специальностей (рост структурной безработицы);

4. политика, проводимая Центральным банком, приводит к сокращению инфляции, путем принесения в жертву реального ВВП;

5. рост ВВП, повышение производительности труда - факторы, которые могут способствовать снижению уровня инфляции в долгосрочном периоде [8], однако для Российской Федерации это пока вызовы.

\section{ЛИТЕРАТУРА}

1. www.economy.gov.ru — Прогноз социально-экономического развития до 2023 года (дата обращения 11.07.2021)

2. www.qks.ru - сайт государственной статистики (дата обращения 10.07.2021)

3. Arthur M. Okun Efficient Disinflationary Policies // American Economic Review 68 (May 1978)

4. Мэнкью Н.Г. Макроэкномика. Пер с англ. - М.: МГУ, 1994

5. Игнатьева 0.В. Трудовая миграция: роль в развитии экономики и государственное регулирование//В сборнике: Материалы Научно-практической конференции с международным участием «Управление в сфере науки, образования и технологического развития» 2016. С. 296-298.

6. Платко А.Ю., Наянов Е.А., Чех Д.О. Экономический рост: национальные проблемы // Экономика и предпринимательство. 2015 № 12-2

7. Молий Г.М., Невежин В.П. Анализ кривой Филлипса для российской экономики // VII Международная студенческая электронная конференция «Студенческий научный форум» - 2015

8. Доронина Ю.Ю., Игнатьева О.В. Развитие человеческих ресурсов. Монография. Москва, 2012.

(c) Ужаков Демьян ( mister-231996@mail.ru ),

Наянов Евгений Александрович ( e.a.nayanov@mospolytech.ru ),Игнатьева Ольга Валерьевна ( oignatyeva@mail.ru ).

журнал «Современная наука: актуальные проблемы теории и практики» 